\title{
DOS CONCEPCIONES DE LOS PRINCIPIOS. UNA RESPUESTA A JUAN RUIZ MANERO*
}

\author{
Luigi Ferrajoli \\ Universidad Roma III
}

RESUMEN. En este trabajo el autor replica a las críticas formuladas por J. RUIz MANERo en el artículo "A propósito de un último texto de Luigi Ferrajoli. Una nota sobre reglas, principios, "soluciones en abstracto" y "ponderaciones equitativas"», publicado en el número precedente de Doxa. El autor examina las diversas críticas dirigidas por RUIz MANERO, tanto en relación con su tipología de las normas regulativas como en lo que se refiere a sus tesis sobre las maneras de resolver las situaciones de conflicto (o concurso) entre principios. La conclusión central a la que llega el autor puede resumirse en lo siguiente: no infravalora en absoluto lo que llama «las buenas razones señaladas por Ruiz Manero en apoyo del enfoque principialista»; piensa, sin embargo, que todas estas ventajas pueden ser alcanzadas también por el enfoque garantista que él defiende, sin que este último enfoque tenga que pagar los importantes precios, sobre todo en relación con el debilitamiento de la normatividad de los principios constitucionales, que, en su opinión, vienen impuestos al principialismo por la teoría de la ponderación. La teoría de la ponderación, en opinión textual del autor, «permanece como el único impedimento para un buen tratado de paz entre nuestros diversos enfoques teóricos, basado en la integración de sus aparatos conceptuales y en la suma de sus buenas razones».

Palabras clave: conflictos (concursos) entre principios constitucionales, principialismo, garantismo, teoría de la ponderación, FerRajoli, Ruiz MANero.

\section{Two Conceptions of Principles. A Response to Juan Ruiz Manero}

ABSTRACT. In this paper, the author answers the criticisms put forward by J. RUIZ MANERO in his article «A propósito de un último texto de Luigi Ferrajoli. Una nota sobre reglas, principios, "soluciones en abstracto" y "ponderaciones equitativas" ", published in the last issue of Doxa. The author examines the various criticisms made by RUIZ MANERO, directed at both his typology of regulative norms and his thesis regarding the ways of solving conflicts or concurrency situations between constitutional principles. The author's main conclusion can be summed up as follows: He does not by any means under values what he calls «the good reasons pointed out by Ruiz Manero in support of the principlist approach». He thinks, however, that all these advantages can also be achieved by means of his guarantee approach, without the latter having to pay the considerable costs which, in his opinion, the theory of balancing impose on the principlist approach, mainly the weakening of the normativity of constitutional principles. In the author's textual opinion, the theory of balancing «is the only obstacle to a good peace treaty between our different theoretical approaches, based on the integration of their conceptual apparatus' and the sum of their good reasons".

Keywords: conflicts (concurrences) of constitutional principles, principlism, guaranteeism, theory of balancing, Ferrajoli, Ruiz Manero.

\footnotetext{
* Fecha de recepción: 30 de octubre de 2013. Fecha de aceptación: 25 de noviembre de 2013.
} 


\section{ACUERDOS Y DESACUERDOS}

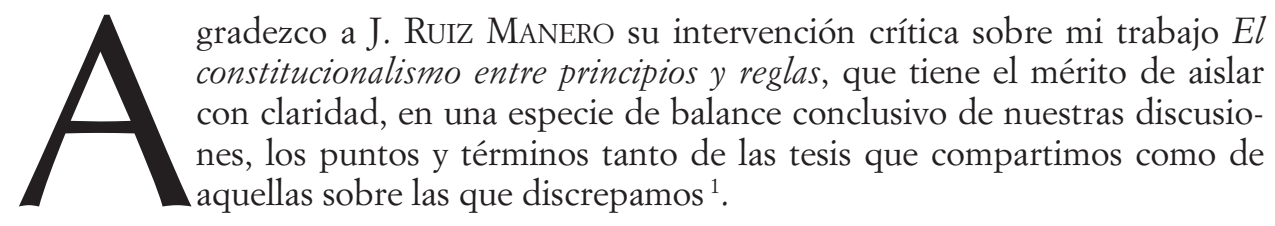

J. RUIZ MANERO parte de una premisa: la categoría de los que yo he llamado «principios regulativos», en la que entran, a mi parecer, casi todos los derechos fundamentales, es «coextensiva», pero no «cointensiva» con la categoría de los que él y M. ATIENZA han llamado «principios en sentido estricto» ${ }^{2}$. Estas dos categorías nuestras, que tanto en mi distinción como en la de ATIENZA y RUIZ MANERO se oponen a la categoría de «principios directivos» o «directrices», serían por tanto equivalentes en cuanto al significado extensional, es decir, a la clase de las normas que estas categorías denotan, pero divergentes en cuanto al significado intensional, al definirse con connotados distintos. Tengo alguna duda sobre la compatibilidad de esta equivalencia extensional con esta divergencia intensional, dado que la extensión o significado extensional de un término está siempre determinado por su intensión, es decir, por los connotados que constituyen su significado intensional. Esto no afecta a que la tendencial coincidencia del significado extensional de mis «principios regulativos» con los «principios en sentido estricto» de RUIZ MANERO — expresiones con las que designamos ambos gran parte de las normas constitucionales sustanciales, y en particular casi todos los derechos fundamentales y el principio de igualdad — valga, si no para reducir, cuando menos para circunscribir nuestros desacuerdos y en todo caso para evitar, como escribe RuIZ MANERO, tanto los pseudoacuerdos como los pseudodesacuerdos. En realidad, nuestro disenso se concentra, sobre todo, en la naturaleza de los derechos fundamentales.

1 J. Ruiz MANERo, «A propósito de un último texto de Luigi Ferrajoli. Una nota sobre reglas, principios, "soluciones en abstracto" y "ponderaciones equitativas"», en Doxa, núm. 35, 2012, 819-832, a propósito de mi artículo El constitucionalismo entre principios y reglas, ibid., 791-817. Prosigue en estos textos nuestra discusión, iniciada con nuestro libro Dos modelos de constitucionalismo. Una conversación, Madrid, Trotta, 2012, continuada con la intervención de J. RuIz MANERO, Cuatro manifestaciones de unilateralismo en la obra de Luigi Ferrajoli, en el congreso celebrado en Valencia sobre «Principia iuris» el 25-26 de abril de 2012, publicado en Isonomía, núm. 37, octubre de 2012, 99-112 y, por último con nuestra discusión del 24 de octubre de 2013, desarrollada en el seminario organizado por la Universidad Federico II de Nápoles, a partir del texto de J. RuIZ MANERO, Dos problemas para la ponderación: tensiones irresolubles y principios imponderables.

2 J. Ruiz Manero, A propósito de un último texto, cit., 821. Sobre esta distinción entre «principios en sentido estricto» y «directrices», cfr. M. ATIENZA y J. RuIZ MANERO, Las piezas del derecho. Teoría de los enunciados jurídicos, Barcelona, Ariel, 1996, cap. I, $\$ \$ 1.3$ y 2.2, 5 y 14-15; cap. IV, $\$ 4$, 140-141; cap. VI, $\$ 2$, 166: de acuerdo con esta distinción, los principios en sentido estricto expresan «valores últimos» o sea, las «razones últimas» o «finales» para actuar, y prevalecen por ello, aun siendo ellos también derogables o ponderables, sobre las directrices, que operan, por el contrario, como «razones para actuar de tipo utilitario». Sobre mi distinción entre «principios regulativos» y «principios directivos» o «directrices», reenvío a El constitucionalismo entre principios y reglas, cit., $\mathbb{\$} 4,801-807$, y a La democracia attraverso $i$ diritti. Il costituzionalismo garantista come modelo teorico e come progetto político, Roma-Bari, Laterza, 2013, 111-122. Una discusión amplia entre las dos distinciones y entre las concepciones de las normas que respaldan a una y a otra se encuentra en L. FERRAJOLI y J. Ruiz MANERo, Dos modelos de constitucionalismo, cit., 78-119. 


\section{REGLAS Y PRINCIPIOS. CUESTIONES DEFINITORIAS}

Comencemos, pues, por nuestro desacuerdo sobre el significado intensional de «principios regulativos» y de «principios en sentido estricto». En su base se encuentra una diferente concepción de la distinción entre «reglas» y «principios, debida claramente a que son diferentes los aparatos conceptuales utilizados por nosotros.

Según Ruiz MANERO, la distinción entre principios y reglas se basa en una diferencia estructural. En los principios, dice él, falta el antecedente, es decir, la indicación explícita de sus «condiciones de aplicación o caso» ${ }^{3}$. En las reglas, por el contrario, se encuentra siempre un antecedente, identificado por él con un determinado conjunto de propiedades «que resultan independientes de las razones en pro o en contra de la realización de la acción que figura modalizada deónticamente en el consecuente» ${ }^{4}$ : piénsese, por ejemplo, en el respeto (o la violación) en el tráfico rodado de determinados límites de velocidad. En tal caso, si se da el antecedente, «se genera un deber concluyente en el destinatario de la norma de realizar la acción ordenada, sin necesidad de que ese mismo destinatario delibere sobre las razones en pro o en contra de ello» ${ }^{5}$ (en el ejemplo usado, «en pro o en contra de los límites de velocidad»). En suma, a diferencia de lo que sucede en las reglas, en los principios su antecedente «no contiene otra cosa sino que se dé una oportunidad de realizar la acción modalizada deónticamente en el consecuente», de forma que «esta modalización deóntica no pretende, como en el caso de las reglas, ser concluyente sino meramente prima facie», dándose con frecuencia «también la oportunidad de realizar la acción, incompatible con la anterior, ordenada por otro principio» ${ }^{6}$. Un buen ejemplo de esta distinta normatividad de los principios es el conflicto entre la libertad de expresión y el derecho al honor o a la privacidad, resuelto por el Tribunal constitucional español con una ponderación, cuyo resultado ha sido la regla con arreglo a la cual se exigen tres condiciones para que la primera prevalezca sobre el segundo: que la información tenga relevancia pública, que sea veraz, y que se formule sin emplear expresiones injuriosas ${ }^{7}$.

Tengo algunas dudas sobre el carácter realmente estructural de una distinción semejante. Podría observarse que la tesis de la existencia de un antecedente determinado en las reglas y de su inexistencia en los principios no siempre es verdadera, sino que depende de cómo están formuladas las normas. Por un lado, en realidad, no es verdad que el destinatario de la norma sobre los límites de velocidad no pueda valorar las razones que apoyan o que se oponen a su observancia: el límite de velocidad bien puede superarse si llevo a un enfermo grave al servicio de urgencia. Por otro lado, las condiciones exigidas por el Tribunal constitucional para la prevalencia de la libertad de manifestación del pensamiento sobre el derecho al honor, bien podrían, en vez de haber sido expresadas por una norma jurisprudencial, haber sido explicitadas en forma de reglas por las mismas normas constitucionales, de acuerdo con la aspiración, que yo he formulado muchas veces, a una formulación de éstas tan precisa como resul-

\footnotetext{
3 J. Ruiz MANero, A propósito de un último texto, cit., 822.

4 Ibid.

5 Ibid.

${ }^{6}$ Ibid.

7 Id., 823.
} 
te posible. Tendríamos en tal caso reglas «relativamente estables», según la expresión utilizada por RUIZ MANERO — con seguridad más estables, y por ello, a mi parecer, preferibles a las normas del texto constitucional-, aunque no fueran «absolutamente estables» ${ }^{8}$, pues no pueden ser tales no sólo los principios sino ni siquiera las reglas: cualquier obligación o prohibición puede, en realidad, resultar derogable cuando se presenten, dice RUIZ MANERO, «propiedades adicionales» ${ }^{9}$ o condiciones, como por ejemplo el estado de necesidad, cuya presencia, habitualmente prevista por normas especiales, se remite obviamente a la valoración del juez. Añado, incidentalmente, que en contra de la opinión corriente, no pienso que los principios hagan «uso de términos fuertemente valorativos» ${ }^{10}$ más que lo hacen las reglas: aquellos enuncian valores, pero los términos en los que los enuncian — libertad de constricciones, igualdad, asistencia sanitaria, instrucción elemental — no son, de por sí, valorativos y están dotados de una extensión relativamente determinada.

Mucho más estructural, me parece, es la distinción propuesta por mí. Entiendo por «reglas» aquellas normas respecto de las cuales son configurables la violación y la observancia: entendidas en este sentido, entran dentro de ellas también la mayor parte de los derechos fundamentales y el principio de igualdad, que, por ello, he llamado «principios regulativos». Entiendo, por el contrario, por «principios directivos» o «directrices», aquellas normas respecto de las cuales no son configurables actuaciones o violaciones específicas consistentes en comportamientos determinados: por ejemplo, la norma expresada por el art. 1 de la Constitución italiana que afirma que «Italia es una República fundada en el trabajo», o la formulada en el art. 3, párrafo $2 .^{\circ}$, con arreglo a la cual «es tarea de la República remover los obstáculos, etc.», o bien las normas sobre la promoción de la cultura, la tutela del paisaje y del patrimonio histórico y artístico, la protección de la maternidad y de la infancia, la tutela del ahorro previstas por los arts. 9, 31 y 47 de la Constitución ${ }^{11}$. Es esta, añado, una definición de las reglas (y, por oposición, de las directrices que no consisten en reglas) no muy distinta, sino sólo más precisa, me parece, de las adoptadas por muchos principialistas: su aplicabilidad en la forma todo-o-nada según la tesis de DwORKIN, su realizabilidad o no realizabilidad según la noción de ALEXY, su forma cerrada y no abierta según la definición sugerida por ATIENZA y RUIZ MANERO, su referencia a supuestos de hecho subsumibles en ellas según la noción propuesta por ZAGREBELSKI ${ }^{12}$.

Pero es también una definición que, aunque distinta, se compadece plenamente con la definición de «reglas» propuesta por RuIZ MANERO, basada en la presencia en ellas de un antecedente, ausente en cambio en los principios. ¿Qué es, en realidad, el antecedente de las reglas, cuya carencia en los principios constituiría lo que diferencia

\footnotetext{
8 Ibid

9 Ibid.

10 Ibid.

11 Remito, sobre esta distinción, a El constitucionalismo, cit., $\$ \$ 4$ y 5, 800-807, y a La democracia attraverso $i$ diritti, cit., $\mathbb{S} 3.4$ y 3.5, 109-112 y 117-120.

12 Cfr. R. Dworkin, I diritti presisulserio (1977), trad. it. de G. ReBUfFA, Bologna, Il Mulino, 1982, 93, 94 y 96; R. AleXY, Teoria dei diritti fondamentali (1994), trad. it. de L. DI CARLO, Bologna, Il Mulino, 2012, cap. III, \$1.2, 106-107; M. ATIENZA y J. RUIZ MANERO, Las piezas del derecho. Teoría de los enunciados jurídicos, Barcelona, Ariel, 1996, cap. I, \$2.1, 9; G. ZAGREBESLKY, Il diritto mite. Legge, diritti, giustizia, Torino, Einaudi, 1992, cap. VI, 149.
} 
las dos clases de normas? Es el comportamiento deónticamente modalizado como prohibido o como obligatorio y al que el ordenamiento conecta efectos jurídicos. Pero este comportamiento es exactamente el mismo que constituye el objeto de la correspondiente expectativa negativa o positiva en la que consiste el derecho fundamental formulado por el principio. Expectativas (positivas y negativas) y deberes correspondientes (obligaciones o prohibiciones) tienen en realidad exactamente la misma materia: las expectativas positivas (o negativas) de un comportamiento determinado equivalen a la obligación (o a la prohibición) del mismo comportamiento atribuidas a otro sujeto ${ }^{13}$. Tan es así que frente a su violación el principio que enuncia un derecho fundamental se transforma en una regla: en una prohibición si consiste en un derecho negativo a la no lesión, como son todos los derechos de libertad; en una obligación si consiste en un derecho positivo a una prestación, como son todos los derechos sociales. Por ejemplo, la libertad de manifestación del pensamiento o el principio de igualdad, que consisten en la expectativa negativa de la no limitación de la primera y de la no discriminación en violación del segundo, se manifiestan, frente a sus violaciones por parte del legislador, como las correlativas prohibiciones de limitación y de discriminación. Análogamente, el derecho a la salud o a la educación, que consisten en la expectativa positiva de la prestación sanitaria o de la escolar, se manifiestan, frente a sus incumplimientos legislativos, como las obligaciones de prestación correspondientes a ellos: precisamente, las violaciones del primer tipo generan antinomias cuya anulación se encomienda a la jurisdicción constitucional; las violaciones del segundo tipo generan lagunas cuya superación se encomienda a la legislación de actuación ${ }^{14}$. Por lo demás, sobre todo en las declaraciones de derechos del siglo XVIII, estas mismas normas fueron expresadas con frecuencia en forma de reglas, esto es, no ya de derechos sino de prohibiciones abstractas perfectamente equivalentes a los derechos universales correspondientes: «El Congreso no podrá hacer ninguna ley para el reconocimiento de cualquier religión, o para prohibir el libre culto de la misma, o para limitar la libertad de palabra, o de prensa, etc.», afirma la primera enmienda de la Constitución de los Estados Unidos; «nadie puede ser acusado, detenido o encarcelado sino en los casos determinados por la ley», establece el art. 7 de la Declaración francesa de 1789; «nadie deber ser incomodado por sus opiniones, inclusive religiosas», añade el art. 10 de la misma Declaración.

La diferencia entre las reglas no formuladas en forma de principios, que ahora bien podemos llamar reglas de comportamiento, y los principios, sean estos principios regulativos o directrices, consiste en el hecho de que en las primeras se indica expresamente el comportamiento calificado deónticamente, mientras que en los segundos se indican expresamente, como ha subrayado bien G. PINO, los fines, los valores y las opciones ético-políticas que el ordenamiento trata de perseguir ${ }^{15}$. Hay solo una diferencia de estilo entre reglas de comportamiento y principios regulativos, como son casi todos los dere-

13 Remito, sobre este punto, a Principia iuris. Teoria del diritto e della democrazia, 3 vols., Roma-Bari, Laterza, 2007, vol. I, Teoria del diritto, $\$ 2.3,151-157$ y, en particular, a los teoremas T2.60 y T2.61 $-(x)\left(\left(\exists y^{\prime}\right)\right.$ ASP $\left.y^{\prime} x\left(\exists y^{\prime \prime}\right) \mathrm{OBL} y^{\prime \prime} x\right)$ y $(x)\left(\left(\exists y^{\prime}\right) \mathrm{ASP} y^{\prime} \perp x\left(\exists y^{\prime \prime}\right) \mathrm{DIV} y^{\prime \prime} x\right)$ — sobre la correlación biunívoca entre las expectativas positivas o negativas, en las que consisten todos los derechos, y las obligaciones y prohibiciones de los mismos comportamientos correspondientes a aquellas.

${ }^{14}$ Cfr., sobre este punto, L. FerRajoli y J. Ruiz Manero, Dos modelos de constitucionalismo, cit., 42-45 y $47-51$.

15 G. PINo, Diritti e interpretazione. Il ragionamento giuridico nello Stato costituzionale, Bologna, Il Mulino, 2010, 52 y 130-131. 
chos fundamentales, formulados como expectativas positivas o negativas de los mismos comportamientos, aunque no aparezcan indicados expresamente, que son objeto de las obligaciones o prohibiciones expresadas por las correspondientes reglas de comportamiento. Hay, por el contrario, una diferencia de estructura entre reglas y principios directivos, en los que no es reconocible ningún antecedente. En realidad, en principios del tipo «Italia es una República fundada sobre el trabajo», o «la República promueve el desarrollo de la cultura» $\mathrm{O}$ «tutela el paisaje» o «estimula y tutela el ahorro», no existen ni antecedentes ni consecuentes, al no ser identificables en ellos ni expectativas específicas, ni obligaciones o prohibiciones correspondientes a ellas, ni comportamientos que sean actuaciones o violaciones de los mismos. Se trata, precisamente, de normas que estipulan políticas públicas, valorables sobre la base de sus resultados y no ciertamente sobre la base de las conductas, indeterminadas e indeterminables, que se dirigen a realizarlos en el mayor grado posible. Pero ciertamente no forman parte de ellas los derechos fundamentales que consisten en expectativas negativas o positivas de comportamientos determinados y que consisten, por ello, en principios regulativos o reglas. Aun si, ciertamente, no basta el uso de la palabra «derecho» para que nos encontremos frente a una regla: por ejemplo, el «derecho al trabajo» previsto por el art. 4 de la Constitución italiana, al no ser configurable ni una obligación específica correspondiente a él, ni comportamientos específicos que sean su cumplimiento o su violación, no es una regla sino un principio directivo, o sea, una directriz: la directriz del pleno empleo que los poderes públicos deben procurar con políticas adecuadas.

El problema, dice J. Ruiz MANERO, depende de mi deficiente definición de las reglas deónticas, que haría referencia sólo al consecuente de las mismas y no también a su antecedente ${ }^{16}$; hasta tal punto que la «propuesta de paz» entre nosotros, propuesta como hipótesis por él sobre la base de la distinción entre «reglas deónticas con antecedente abierto», es decir, indeterminado y determinable únicamente sobre la base de una ponderación entre principios, y «reglas deónticas con antecedente cerrado» resulta, dice RuIZ MANERO, inaceptable, dado que «no hay, en mi construcción [en la de FERRAJOLI], espacio para normas con antecedente abierto» ${ }^{17}$. Esto es verdad, pero depende simplemente del hecho de que nuestros aparatos conceptuales son distintos. Normas con «antecedente abierto» no son otra cosa, en la terminología de RuIz MANERO, sino los principios en el sentido definido por él, es decir, como normas que permiten la determinación de la regla aplicable no ya prima facie, sino solamente tras su ponderación con otros principios ${ }^{18}$. La crítica de RUIZ MANERO se revela por eso como una clásica «petición de principio»: precisamente del principio que consiste en su noción de «principios» y de su distinción entre reglas y principios, que son exactamente las tesis que yo no comparto. Consiste, por decirlo brevemente, en el hecho de que «no hay espacio, en mi construcción [de FERRAJOLI], para la "versión estándar" del principialismo», de la que precisamente estamos discutiendo. En mi aparato conceptual, en efecto, los que he llamado «principios regulativos» y que RUIZ MANERO llama «principios en sentido estricto», y que incluyen casi todos los derechos fundamentales, son, a

16 J. Ruiz Manero, A propósito, cit., 824-825.

17 Id., 827 .

18 Id., 824 y 826-827. Cfr. también M. AtIEnZA y J. Ruiz MANERO, Las piezas del derecho, cit., cap. I,

$\$ 2.1 .1,9$. 
mi parecer, una subclase de las reglas, en el sentido de «reglas» que he precisado antes y que es bastante más amplio que la noción de reglas propuesta por los principialistas. Entendidas las reglas en este sentido, sus posibles conflictos - o mejor, concursosadmiten las soluciones, en abstracto o en concreto, que he ilustrado en el texto que ha dado origen a esta discusión.

\section{SOLUCIONES EN ABSTRACTO Y CONCURSOS DE NORMAS}

Vengo así al segundo orden de críticas que me dirige Ruiz MANERO: el relativo a las soluciones, en abstracto y en concreto, de los posibles conflictos, o por mejor decir concursos, entre principios. Las soluciones en abstracto son las propuestas por la teoría o la doctrina jurídica con argumentos que se presentan como válidos de una vez para siempre, aunque obviamente opinables, y ya no según la singularidad de los casos. Las soluciones en concreto son, por el contrario, aquellas a las que se recurre cuando no son posibles las soluciones en abstracto y son el fruto de una valoración equitativa de las circunstancias singulares de los casos en cuestión.

Permiten soluciones en abstracto, a mi parecer, al menos dos tipos de concursos, en los que los derechos establecidos por algunas normas operan como límites al ejercicio de los derechos establecidos por otras, dando lugar así a otras tantas jerarquías: no ya — préstese atención — entre derechos, todos de ordinario del mismo rango constitucional, sino entre algunos derechos y el ejercicio de otros, que por ello se ubica en un nivel normativo más bajo que aquel al que pertenecen los derechos mismos. RuIZ MANERO ha criticado estas dos jerarquías.

Comencemos por la primera, la que se da entre derechos fundamentales consistentes solamente en inmunidades y el ejercicio de otros derechos. Las inmunidades fundamentales - como la libertad de pensamiento o de conciencia o la inmunidad frente a las torturas - son límites, a mi parecer, no limitables por el ejercicio de ningún poder ni tampoco por el ejercicio de otros derechos. Estos son, en efecto, derechos consistentes solamente en expectativas de no lesión y no también en facultades ni, aún menos, en poderes: no admiten, por tanto, ningún comportamiento que sea ejercicio de los mismos y que pueda, por ello, interferir en la vida de otros. Pero RuIz MANERO alude a la hipótesis ya recordada del conflicto o concurso entre la libertad de información, por un lado, y, por otro, los derechos a la intimidad y al honor de las personas, lesionados ambos por difamaciones o por interferencias en la vida íntima ${ }^{19}$. Pues bien, no tengo ninguna dificultad en reconocer lo fundado de esta objeción por lo que se refiere a las inmunidades fundamentales que consisten en los derechos a la intimidad $\mathrm{y}$ al honor ${ }^{20}$. Y le agradezco por ello: mi tesis relativa a esta primera jerarquía no es, evidentemente, generalizable a todas las inmunidades, y no se aplica al concurso, sobre el que volveré en el próximo apartado, entre la libertad de información y el derecho a la inviolabilidad de la intimidad y del honor.

Esta crítica no vale, sin embargo, para las inmunidades más importantes, como la libertad de conciencia y de pensamiento o la inmunidad frente a las torturas, que

19 Ibid., 823 y 831.

20 Lo he hecho ya en La democracia attraverso $i$ diritti, cit., 123, nota 43. 
son derechos que consisten en libertades puramente negativas, de las cuales, al poder convivir las mismas con las libertades ajenas según la célebre fórmula kantiana ${ }^{21}$, no se justifican limitaciones como garantía de otros derechos. Son «principios imponderables», según la eficaz expresión utilizada recientemente por RUIZ MANERO a propósito del principio de dignidad personal: imponderables hasta el punto, dice él, de que sería un «oxímoron» hablar de «conductas justificadas (por un determinado principio), contrarias al principio de dignidad humana» ${ }^{22}$. Un oxímoron no menos estridente sería también, en realidad, una frase del tipo «conducta justificada, aun si contraria a los derechos a la libertad de conciencia o de pensamiento». En otros casos, la imponderabilidad de las inmunidades fundamentales se encuentra garantizada por reglas rígidas de tutela. No es, en efecto, un oxímoron, aunque sea moralmente torpe, la frase «conducta justificada, aun si contraria a la inmunidad frente a las torturas», pronunciada por cuantos han sostenido la justificación de la tortura en casos excepcionales, como el de la necesidad de hacer hablar a un terrorista al que «sabemos» informado del proyecto de una matanza ${ }^{23}$. Ha sido precisamente para impedir excepciones semejantes por lo que el art. 2.2. ${ }^{\circ}$, de la Convención contra la tortura del 10 de diciembre de 1984 ha establecido que: «En ningún caso podrán invocarse circunstancias excepcionales tales como estado de guerra o amenaza de guerra, inestabilidad política interna o cualquier otra emergencia pública como justificación de la tortura». Dígase lo mismo de otros derechos fundamentales de inmunidad, como el habeas corpus, que, en virtud del principio de legalidad de las penas y de las medidas restrictivas de la libertad personal solamente puede limitarse por medio de reglas taxativamente previstas en la ley.

Hay después una segunda y todavía más importante jerarquía, de carácter más propiamente lógico y estructural: aquella en virtud de la cual el ejercicio de los derechos fundamentales de autonomía privada — préstese atención, no tales derechos, sino su ejercicio-, al consistir en actos negociales de grado subordinado a la ley y todavía más a la Constitución, no puede derogar los derechos fundamentales establecidos por éstas. Contra esta tesis que, como he dicho muchas veces, es una tesis de gramática jurídica, RUIZ MANERO pone el ejemplo del poder del testador para discriminar a alguno de sus herederos por motivos de religión. Pero esta es una hipótesis no pertinente. Con la salvedad de las normas inderogables sobre la cuota legítima de la herencia, en realidad en este caso no hay ningún concurso de normas, ningún derecho, ninguna expectativa de otros que se lesione por la discriminación del testador. El testamento es un acto negocial unilateral, de cuyas disposiciones no se exige al testador motivación ninguna. Aquí nos encontramos frente a un (derecho-)poder conectado al derecho a disponer de los propios bienes patrimoniales: así como al propietario no se le exige en vida que justifique el uso de los bienes de su propiedad, de la misma forma tampoco se le exige que lo justifique en el momento de la muerte. Puede preferir a un hijo porque

21 «Cualquier acción es conforme al derecho cuando por medio de ella, o según su máxima, la libertad del arbitrio de cada uno puede coexistir con la libertad de todos los demás de acuerdo con una ley universal» [I. KANT, La metafísica dei costumi (1797), trad. it. de G. VIDARI, Bari, Laterza, 1970, Introduzione alla dottrina del diritto, C, 35].

${ }^{22}$ En la ponencia del seminario de Nápoles citada en la nota 1, Dos problemas para la ponderación: tensiones irresolubles y principios imponderables.

${ }_{23}$ Es la tesis de A. DERSHOWITZ, Why Terrorism Works. Understanding the Threat Responding to the Challenge (2002), trad. it., Terrorismo, Roma, Carocci, 2003, 118 y ss., y 125 y ss. 
este sea creyente en una determinada religión o por cualquier otro motivo, declarado o no declarado; puede destinar una determinada suma al proselitismo en favor de una cierta fe religiosa o a cualquier otro fin, con tal de que no sea explícitamente ilícito. En estos casos - en los testamentos, del mismo modo que en las donaciones y en las compraventas - no hay en realidad ningún conflicto con otros derechos que requiera de alguna ponderación.

Un posible concurso entre derechos se presenta, por el contrario, en los casos de ejercicio de los derechos civiles en el mercado. Y esto porque tales derechos - contrariamente a su configuración usual como derechos de libertad-, son también poderes, cuyo ejercicio interfiere en la esfera jurídica de otras personas. Es a estos casos, es decir, a los poderes del mercado, a los que me refiero con la tesis de la necesaria subordinación a la ley y a los demás derechos constitucionalmente establecidos de los actos que son ejercicio de los mismos, al ser estos actos de grado o nivel normativo más bajo que el de la ley y aún más que el de la Constitución ${ }^{24}$. Me refiero, precisamente, a los límites impuestos a la actividad contractual y a la iniciativa económica privada con las que se ejercitan estos derechos-poderes, también ellos constitucionalmente establecidos, que son los derechos civiles de autonomía privada: límites impuestos para la tutela de los derechos de los trabajadores contra el poder de otra forma arbitrario de quienes les dan trabajo; para la garantía del ambiente y de los bienes comunes contra su devastación o su apropiación privada; como garantía de la competencia, de la estabilidad y del desarrollo económico, de los intereses públicos y, obviamente, de los derechos fundamentales de todos contra los poderes de otra forma desregulados y salvajes de la economía y la finanza, que hoy no solamente no están subordinados, sino que se encuentran de hecho supraordenados al papel de gobierno de la política y al papel de garantía del derecho.

\section{SOLUCIONES EN CONCRETO Y PONDERACIÓN EQUITATIVA}

Volvamos ahora a la cuestión dilemática suscitada por RUIZ MANERO del concurso entre libertad de información y derecho a la intimidad y/o al honor. En este caso, al no ser la cuestión soluble en abstracto, es posible sólo, como ya he dicho, su solución en concreto, sobre la base de la ponderación equitativa de las circunstancias singulares del hecho en cuestión. Esto es lo que ha hecho, a mi parecer, la óptima norma ya recordada del Tribunal constitucional español sobre las tres condiciones que ella exige para que la libertad de información prevalezca sobre las inmunidades de la intimidad y del honor. Pero esta solución en concreto se basa claramente en la valoración o ponderación no ya de los derechos o principios constitucionales en concurso, sino de los connotados o circunstancias de hecho del caso sometido a juicio, como son, precisamente, las tres

${ }^{24}$ He criticado repetidas veces la confusión corriente, en la noción omnicomprensiva de «derechos civiles», entre los derechos fundamentales de libertad, que consisten en meras inmunidades o facultades, los derechos fundamentales de autonomía privada, que consisten en poderes ejercidos por medio de actos que inciden en la esfera jurídica de otros, y los derechos reales de propiedad que son derechos singulares y disponibles que consisten también en poderes de disposición. Me limito a remitir a Principia iuris, cit., vol. I, Teoria del diritto, $\$ 10.10,635-638$, y $\mathbb{\$} \$ 11.6-11.8,752-772$, y vol. II, Teoria della democrazia, $\$ \$ 14.14-14.21,224-266$. Cfr. también, recientemente, «Libertà e proprietà», en G. ALPA y V. Roppo (eds.), La vocazione civile del giurista. Saggi dedicati a Stefano Rodotà, Roma-Bari, Laterza, 2013, 91-104. 
condiciones antedichas: la relevancia pública de la información, su veracidad y su formulación en términos no injuriosos. El propio RuIZ MANERO lo reconoce indirectamente: por cuanto, dice él, la solución aportada por esta norma es válida en tanto que un nuevo caso individual no presente «propiedades adicionales» ${ }^{25}$. Pero esto quiere decir exactamente lo que yo sostengo: objeto de ponderación no son ya los principios, es decir, las normas en las que estos son formuladas y que siguen siendo siempre las mismas, sino las circunstancias o propiedades adicionales de los hechos previstos por aquellas, hechos que son, por el contrario, siempre diferentes porque singulares e irrepetibles.

RUIZ MANERO declara, sin embargo, no comprender el sentido de la tesis, indebidamente atribuida por mí a los principialistas, según la cual se pesan las normas, o sea, el significado de los enunciados normativos; y no comprender tampoco el sentido de mi tesis según la cual se pesan, en la ponderación equitativa, las circunstancias o propiedades singulares e irrepetibles del hecho juzgado. Lo que se pesan, dice él, son las razones que apoyan una u otra solución de una controversia jurídica ${ }^{26}$. Pero es claro que se trata, en todos estos casos, de expresiones metafóricas, que no tienen ningún sentido si se toman literalmente: no se pesan, en realidad, ni los significados de las normas, ni las circunstancias de los hechos. Pero no se pesan tampoco, frente a lo que escribe J. Ruiz MANERO, las razones que sostienen una decisión. Si he utilizado la expresión «ponderación equitativa» ha sido sólo para seguir la metáfora principialista del peso. Debemos, en lugar de ello, hablar, a propósito de las circunstancias singulares e irrepetibles de los hechos, de «comprensión» y de «valoración». Que son exactamente las expresiones utilizadas por mí a propósito de la equidad: que es un procedimiento cognitivo que consiste, no ya en la verificación jurídica o fáctica, sino, precisamente, en la comprensión de los connotados específicos del caso concreto ${ }^{27}$. En estos términos la tesis sostenida por mí resulta bastante más clara: objeto de valoración o comprensión, a los fines de la solución en concreto de las controversias generadas por el concurso de normas, no son los principios, que son sólo objeto, en cuanto normas jurídicas, de interpretación, ni tampoco las razones, que son objeto de argumentación, sino sólo las circunstancias o propiedades de los casos concretos, siempre singulares e irrepetibles.

\section{LA RELEVANCIA PRÁCTICA DE LA CUESTIÓN}

Deseo precisar, como conclusión de nuestra discusión, que nuestros disensos no excluyen en absoluto la importancia, en el plano teórico, que asocio a la distinción entre reglas y principios y a la teoría de la argumentación. Se trata de dos adquisiciones teóricas fundamentales que debemos al enfoque principialista, tal como ha sido desarrollado por los estudios de M. ATIENZA y de J. RUIZ MANERO. La primera adquisición consiste en un importante desarrollo de la teoría de las normas, que se cifra en la especificación de la categoría de los principios; los cuales, en vez de disciplinar directamente las conductas mediante obligaciones y prohibiciones como hacen las que he llamado

25 J. Ruiz Manero, A propósito, cit., 823.

26 Id., 831-832.

27 Diritto e ragione. Teoria del garantismo penale (1989), Roma-Bari, Laterza, 11. a ed., 2011, cap. III, $\ 11$, 135-147. 
«reglas de comportamiento», formulan los valores perseguidos por ellas: tanto si se trata de principios regulativos, formulados en términos de expectativas (de la comisión o de la omisión de comportamientos ajenos), como, y todavía más, si se trata principios directivos, que dictan no ya comportamientos determinados sino políticas públicas.

La segunda adquisición consiste en el papel fundamental reconocido a los principios en la argumentación jurídica. Todos los principios, sean regulativos o directivos, precisamente porque expresan explícitamente los valores o las finalidades perseguidas por el legislador, son utilizados como argumentos en el razonamiento jurídico y, en particular, en la interpretación sistemática de los enunciados normativos. No sólo. También las reglas, o por lo menos las reglas dotadas de algún sentido funcional (desde las normas penales sobre el homicidio a las prohibiciones de aparcamiento o la luz roja de los semáforos) tienen a sus espaldas principios (el derecho a la vida y la posibilidad del tráfico rodado), que, a su vez, son utilizables como argumentos en el razonamiento y en la interpretación jurídica. En cuanto a los principios regulativos, estos están dotados de una feliz ambivalencia. Son al mismo tiempo reglas y principios: se manifiestan como reglas frente a los comportamientos que son violaciones de los mismos, por comisión o por omisión; se manifiestan, en cambio, como principios cuando se utilizan como argumentos en la argumentación y en la interpretación jurídicas ${ }^{28}$. El papel de los principios es por ello esencial en la producción de lo que he llamado el «derecho viviente», el cual es el fruto de la aplicación del «derecho vigente» ${ }^{29}$, y por ello de la argumentación con que cada vez se motiva la interpretación operativa de los enunciados normativos ${ }^{30}$.

El disenso, además de en mi rechazo del objetivismo ético asociado en diversos sentidos al principialismo, se sitúa, pues, esencialmente, en la teoría de la ponderación, que a mi parecer propone una reconstrucción impropia y desencaminada del razonamiento jurídico. Naturalmente, nuestras tesis — las mías y las de J. RUIZ MANERO- no son ni verdaderas ni falsas. Están más o menos dotadas de alcance empírico y de capacidad explicativa y son más o menos adecuadas para las finalidades reconstructivas del razonamiento jurídico perseguidas por la teoría. A mí me parece que el enfoque que he propuesto yo tiene una capacidad explicativa mayor del que tiene el basado en la ponderación, la cual no es capaz de dar cuenta adecuadamente de las jerarquías de las fuentes y de las normas, del derecho viviente ilegítimo porque en conflicto con

28 Sobre esta ambivalencia de los principios regulativos, remito a El constitucionalismo, cit., $\$$ 5, 805-806, y a La democracia attraverso $i$ diritti, cit., $\$ 3.5,116-120$.

${ }_{29}$ Sobre la distinción entre derecho vigente y derecho viviente, cfr. El constitucionalismo, cit., $\$ 7,812-815$, y La democracia attraverso $i$ diritti, cit., $\mathbb{\$} 3.8,128-133$. La distinción corresponde grosso modo a la formulada por R. Pound entre law in books y law in action (R. Pound, «Law in Books and Law in Action», en American Law Review, 1910,12) y aun antes — como puso de relieve G. TARELLO (Il realismo giuridico americano, Torino, Giuffrè, 1962, 114) — por A. BENTLEY, The Process of Government, reimp. Everston, 1949, 294-297 y 165-172, cuya primera edición es de 1908.

${ }_{30}$ En este sentido, bien puede decirse que el derecho viviente se configura como argumentación, según la eficaz imagen de M. ATIENZA, El derecho como argumentación. Concepciones de la argumentación, Barcelona, Ariel, 2006. He introducido la noción de «interpretación operativa» en oposición a «interpretación doctrinal» - la primera en concreto, a cargo de los operadores jurídicos en la aplicación de las normas a los casos individuales, la segunda en abstracto, a cargo de la doctrina jurídica - en «Interpretazione dottrinale e interpretazione operativa», en Rivista internazionale di filosofía del diritto, fasc. I, enero-marzo de 1966, 290-304; pero vid. también Principia iuris, cit., vol. I, Teoria del diritto, Premessa, 101; $\$$ 4.4, 231-232; $\$$ 6.12, 337-338; $\$$ 9.16, $565-566$ y $\$ 12.8,880-885$. 
aquellas, del correspondiente papel de control del ejercicio ilegítimo de los poderes confiado a la jurisdicción, y también de los que el propio RUIZ MANERO ha llamado «principios imponderables».

Por otro lado, además de una dimensión semántica y de un papel explicativo, nuestras teorías y concepciones tienen una dimensión pragmática y un relevante papel performativo en la construcción misma del edificio jurídico. Ciertamente no infravaloro en absoluto «las buenas razones» señaladas por RUIZ MANERO en apoyo del enfoque principialista: la pretensión de duración larga de los textos constitucionales, entre otras cosas difícilmente modificables, y la necesidad de que los mismos ofrezcan un terreno común compartido para las decisiones públicas; la conveniencia de no cerrar rígidamente su alcance normativo respecto a las deliberaciones sobre los numerosos derechos establecidos por ellos y sobre sus complejas e imprevisibles relaciones; el consiguiente rechazo de la idea de que la constitución pueda disciplinar anticipadamente todas las posibles combinaciones de propiedades relevantes que puedan presentar los casos futuros $^{31}$. Estoy convencido, sin embargo, de que todas estas ventajas pueden ser alcanzadas también por el enfoque garantista, sobre la base de las formas tradicionales de la interpretación sistemática y de la interpretación evolutiva, una y otra apoyadas por una buena teoría de la argumentación como la elaborada por el enfoque principialista, pero depurada de la teoría de la ponderación.

Pero pienso, sobre todo, que no podemos ignorar, en la valoración de la dimensión pragmática de nuestros distintos enfoques teóricos, los precios que implica la reconstrucción del razonamiento jurídico llevada a cabo por la doctrina principialista de la ponderación: el debilitamiento de la normatividad de los principios constitucionales, entendidos no ya como reglas que imponen su respeto o su actuación legislativa y su aplicación jurisdiccional, sino como principios ponderables, y por ello confiados a las opciones ponderadas de los operadores jurídicos; la consiguiente inversión de la jerarquía de las fuentes, al ser tales opciones, conjuntamente con las reglas que son el fruto de la ponderación entre principios, producidas por operadores - legisladores y jueces- que deberían estar subordinados a esos principios, si son de rango constitucional; el papel activo y creativo que por ello resulta confiado a la jurisdicción, en contraste con su sujeción a la ley y con la separación de poderes. Son precios demasiado altos, me parece, para una teoría no necesaria y desencaminada como la de la ponderación entre principios; la cual, por tanto, permanece como el único impedimento para un buen tratado de paz entre nuestros diversos enfoques teóricos, basado en la integración de sus aparatos conceptuales y en la suma de sus buenas razones.

(Traducción de Ángeles Ródenas)

31 J. Ruiz Manero, A propósito, cit., 823. 